\title{
Synthesis of PLK4 Inhibitor CFI-400945
}

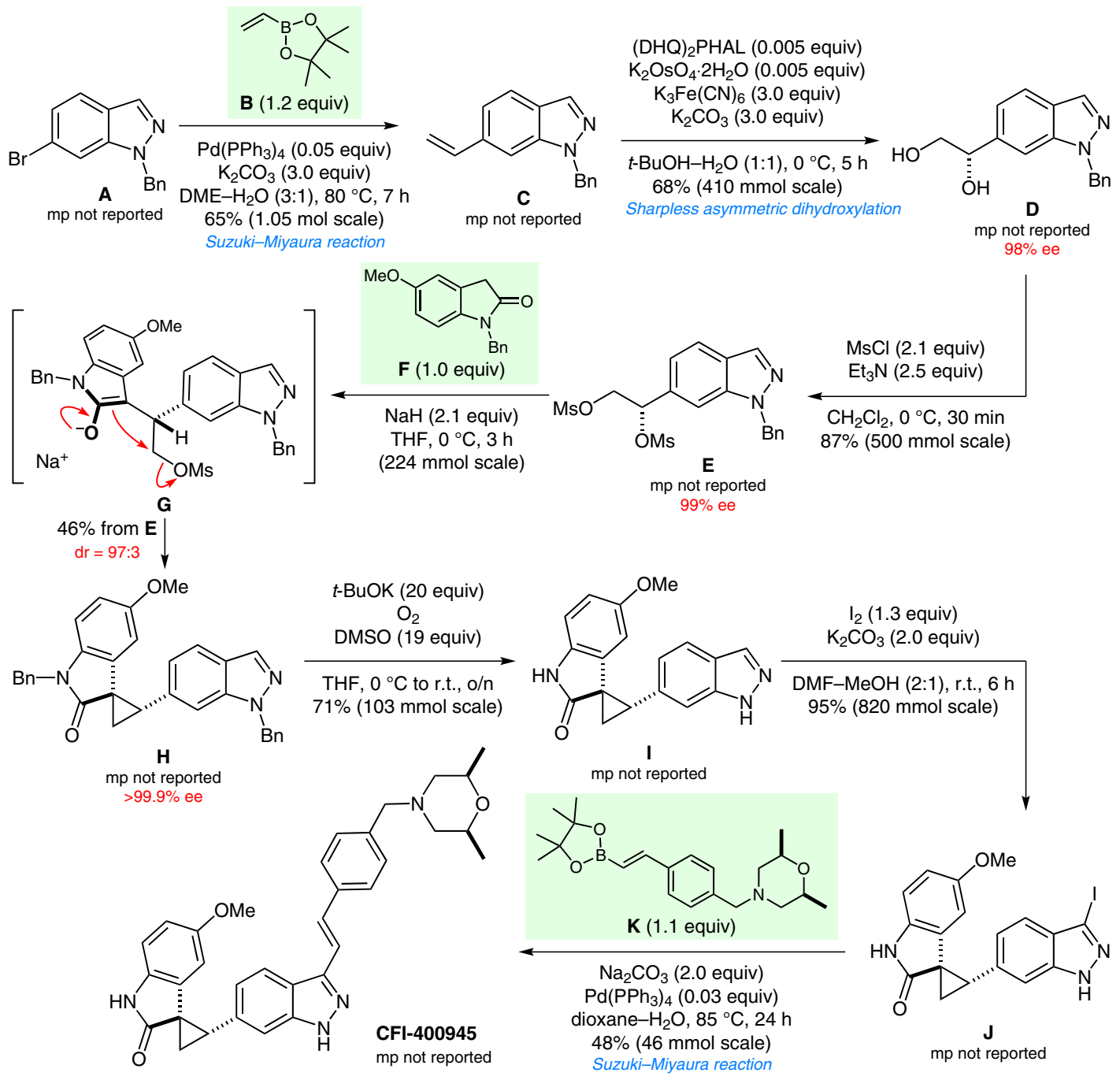

Synthesis of Natural

Products and

Potential Drugs

\section{Key words}

\section{CFI-400946}

Polo-like kinase 4 inhibitors

cyclopropanation

Sharpless

asymmetric

dihydroxylation

Suzuki-Miyaura

coupling

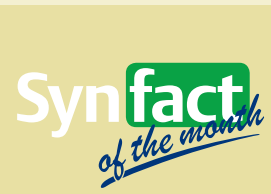

Significance: $\mathrm{CFI}-400945$ is an inhibitor of Pololike kinase 4 (PLK4) that is a lead for the treatment of various cancers. The synthesis depicted features a diastereoselective one-pot double $\mathrm{S}_{\mathrm{N}} 2$ displacement reaction $(\mathbf{E} \rightarrow \mathbf{H})$ for the creation of the cyclopropane ring. The authors propose that the stereoselectivity of the cyclopropanation is a consequence of $\pi-\pi$ interactions that stabilize conformer $\mathbf{G}$.

SYNFACTS Contributors: Philip Kocienski

Synfacts 2015, 11(4), 0345 Published online: 18.03.2015 Dol: 10.1055/s-0034-1380330; Reg-No.: K00915SF
Comment: Attempted hydrogenolysis of the benzyl protecting groups from a close relative of $\mathbf{H}$ was accompanied by partial ring opening of the cyclopropane. However, the benzyl groups were removed cleanly using potassium tert-butoxide in an oxygen-saturated solution in THF and DMSO (R. M. Williams, E. Kwast Tetrahedron Lett. 1989, 30, 451). 